\title{
O DISCURSO PANEGIRÍSTICO E A LEGITIMAÇÃO DO PODER NO SÉCULO IV D.C.
}

\author{
Ana Paula Franchi
}

RESUMO: Este artigo procura discutir a questão da legitimação do poder imperial no século IV d.C no Império Romano, em um momento onde as bases da organização imperial convertem-se paulatinamente em uma estrutura de poder centralizada no soberano, baseada em uma monarquia de direito divino. Neste sentido, procura-se trabalhar a questão da reestruturação teórica e ideológica acerca do poder e legitimidade do imperador, com destaque no campo da comunicação, essencialmente na questão da propaganda política imperial.

PALAVRAS-CHAVE: discurso panegirístico; legitimação do poder real; Império Romano, século IV d.C.

Como principal objetivo deste artigo, procura-se abordar a questão da legitimação do poder imperial romano no século IV d.C.. O interesse por esta questão surgiu a partir da constatação de um movimento particular na história do Império Romano. Foi neste período, que engloba o século III d.C. e IV d.C. principalmente, que as bases que fundamentavam a dominação romana, como o ideal de cidadão a partir da res publica, converteram-se paulatinamente em uma estrutura de poder centralizada no Imperador, fortemente influenciada pelas organizações monárquicas orientais e helenísticas.

Neste sentido é perceptível uma crescente participação das elites provincianas na política imperial, entre outros fatores, justificada pela ampla participação das mesmas no exército romano, e, ao mesmo tempo, uma conjuntura de crise configurada pela série de usurpações do poder decorridas desta influência. Estas questões contribuíram para o abalo da legitimidade do poder imperial.

Foi neste sentido que a reestruturação teórica e ideológica acerca do poder e legitimidade do soberano passou a ser amplamente trabalhada em diversos setores, e em destaque, o campo da 
comunicação, essencialmente a produção literária oficial do Império, com um caráter enfático em relação à propaganda da política imperial e à promoção dos fundamentos do Dominato.

Um dos gêneros estilísticos que se sobressaiu e auxiliou na fundamentação deste período foram textos discursivos com uma característica laudatória particular, conhecidos como panegíricos. Este gênero foi extremamente recorrente dentre as diversas produções escritas, tanto no mundo grego quanto no Império Romano.

Diversos estudiosos procuraram, desta maneira, ressaltar estas composições como importantes fontes de análise histórica, transpondo os limites da literatura e estética tal qual a compreendemos atualmente, por fazerem referência principalmente às atitudes políticas dos imperadores. Procuramos considerar que este tipo de produção literária, que fundamentava a comunicação e propaganda imperial, pode ser apresentada como um instrumento ativo de poder, ao invés de simplesmente refletir uma dada realidade política e social.

Porém, não podemos restringir este gênero discursivo à Antigüidade Tardia: os panegíricos eram discursos comuns no âmbito da antigüidade como um todo. $O$ nome pelo qual são chamados pertence à linguagem da retórica grega, sendo designado originalmente como um habitual complemento das assembléias solenes, fundamentado pela oratória e retórica.

No mundo romano, a "teoria da arte de falar", ou seja, retórica e oratória, também eram utilizadas de forma ampla pelos intelectuais, e enriqueceram-se com as influências trazidas pela helenização. Passaram rapidamente a serem empregadas como parte de uma educação mais avançada, o que permitiu a utilização destas técnicas em muitos casos, por grupos pertencentes aos altos estratos sociais em prol da fundamentação teórica da política imperial, que no caso do nosso recorte temporal, tinha um caráter monárquico

Tendo a laudatio, sob a forma de elogios aos imperadores, como uma de suas principais características, os discursos panegirísticos procuravam fundamentar a política imperial, 
transformando-se em eficientes instrumentos propagandísticos, o que remete a um aumento considerável do número de produções deste tipo em um curto intervalo de tempo, sendo estes discursos considerados como obrigatórios após algum acontecimento ou atitude "gloriosa" por parte do imperador.

Eram pronunciados, por exemplo, após a ascensão ao poder de algum aspirante ao Império, nas comemorações de aniversário de elevação do soberano à púrpura e, em muitos casos, após campanhas militares vitoriosas contra os inimigos do Estado.

Como expressão da composição destes discursos em um curto espaço de tempo, podemos observar a existência de uma coletânea de discursos pronunciados entre os anos de 289 d.C. e 389 d.C. que tem seu conteúdo transitando desde homenagens a Diocleciano e Maximiano, chegando até os tempos de Teodósio ${ }^{1}$.

Logo, enfatiza-se que os discursos panegirísticos eram utilizados como instrumentos de promoção ideológica, uma vez que a preocupação de seus autores, principalmente nas obras em homenagem ao imperador Constantino, centrava-se na fundamentação da organização do Dominato e também na boa aceitação desta nova estrutura de caráter monárquico perante a sociedade imperial como um todo.

Acreditamos que os discursos, em sua definição, podem ser entendidos como uma combinação de elementos lingüísticos, onde o respectivo autor/orador exprime através do conteúdo da obra seus pensamentos e também sua ação sobre o mundo. No caso particular dos panegíricos, em decorrência de sua função inicial de comunicação imperial, sua ampla utilização acabou atingindo todos os níveis das relações sociais, manifestando-se como um elemento favorável à consolidação da ideologia imperial.

${ }^{1}$ Para a análise destes discursos foram utilizadas as obras de GALLETIER, E. Panégyriques Latins. Paris: Société d’edition “Les Belles Lettres”, 1952. Tomo I e II., e LLORENTE, Victor-Jose H. Biografos y Panegiristas Latinos. Madrid: Aguilar, 1969. 
No que envolve as questões acerca da ideologia, procuramos compreendê-la como algo que transcende o campo puro das idéias, o que nos conduz a partilhar dos pensamentos de Eliana R. de Freitas Dutra, que entende que “(...) as ideologias tentam tornar as situações sociais compreensíveis, e construí-las de tal maneira, que seja possível agir dentro de seu quadro"2. Refletida sobre este viés, entende-se que a questão ideológica acaba por atuar no campo da produção de sentidos, na sua circulação e sua recepção.

Ponderando estas questões, pode-se compreender que a função ideológica dos panegíricos consiste em uma definição do quadro imperial romano ao mesmo tempo em que procura construir as bases do sistema emergente do Dominato, através da defesa da constituição de dinastias familiares e hereditárias, fundamentadas na questão do poder por direito divino.

Os panegiristas buscavam fundamentar estes ideais através de abordagens que prefiguram a imagem do homenageado em questão, por meio do resgate de vínculos que estabelecem ligações entre o presente e o passado, utilizando-se do ideal da tradição enquanto fonte legitimadora deste novo contexto político.

Como exemplo destas ponderações, observamos, por exemplo, no discurso pronunciado no ano de 310 d.C. "Panegirico de Constantino" que este resgate concretiza-se, entre outros argumentos, na construção de uma linhagem familiar que remete o imperador Constantino a Cláudio, o Gótico, personagem que conquistou grande fama entre os habitantes do império ao sair vitorioso na batalha contra o avanço dos bárbaros na Anarquia Militar.

No entanto, no decorrer da história do Império Romano, a utilização deste saber enquanto instrumento de comunicação oficial por parte do poder central ganhou força, o que acabou condicionando boa parte da produção literária em prol do interesse deste grupo.

\footnotetext{
${ }^{2}$ DUTRA, E. R. de F. História e culturas políticas: definições, usos genealogias. In: Varia História, Belo Horizonte, n. 28, p. 13-28, dez. 2002, p. 17.
} 
No domínio da produção panegirística, é fato que os discursos eram encomendados aos melhores oradores e na grande maioria das vezes estes oradores teriam sido indicados pelo próprio imperador, evento que poderia ocasionar que o conteúdo das obras fosse composto por declarações políticas orientadas diretamente pelo soberano ou que o texto final passasse pelo seu aval.

Ao iniciar sua abordagem a respeito do levante de Maximiano contra Constantino no ano de 310 d.C., o orador do "Panegirico de Constantino" deixa clara esta possibilidade de interferência do poder imperial na composição destas obras, porém, procura relativizá-la ao expressar esta questão sob a forma de um "pedido de conselho":

Tales eran los trabajos que, en beneficio y prestigio del imperio, retenían tu atención cuando las nuevas agitaciones de aquel hombre, que más que nadie hubiera debido favorecer tus exitos, las desviaron hacia él. Todavía no sé demasiado bien de qué manera he de hablar de él y espero un consejo de un gesto de tu divinidad. ${ }^{3}$

Mesmo considerando o fato da maioria dos oradores pertencerem a um estrato social elevado, com efetiva participação no sistema de dominação romano, percebemos através de suas obras a intenção de se posicionarem enquanto porta-vozes de uma opinião geral da sociedade imperial.

Como procuravam legitimar esta prática da política imperial com bases monárquicas, buscavam construir um ideal acerca do soberano que afirmava-se oriundo do pensamento coletivo. Esta estratégia conduziria a uma suposta unificação e um nivelamento das opiniões dos diferentes grupos sociais que compunham o Império, possibilitando a consolidação da política do Dominato nos moldes das monarquias helênicas sem maiores conflitos.

Como principal fundamento desta abordagem, foi selecionado dentre os discursos da coletânea utilizada, as obras em homenagem ao imperador Constantino, sendo elas: "Panegirico en honor de

3 An., Paneg. 310 (XIV, 1) In: LLORENTE, Victor-Jose H. Biografos $y$ Panegiristas Latinos. Madrid: Aguilar, 1969, p. 1224. 
Maximiano y Constantino" (307 d.C.), "Panegírico de Constantino" (310 d.C.) "Discurso de accion de gracias, dirigido a Constantino Augusto" (312 d.C.), "Panegirico en honor de Constantino" (313 d.C.) e o "Panegirico de Constantino Augusto" (321 d.C.)..

Esta escolha deve-se não só pelo fato de que este imperador foi objeto de grande parte dos discursos, mas também por entender que ao estudá-lo pode-se compreender a consolidação da mudança político-ideológica do Dominato e conseqüentemente a teorização da concentração de poder em torno de um único representante monárquico.

Boa parte dos discursos desta coletânea, de acordo com E. Galletier ${ }^{4}$, foi pronunciada em cidades fora da península itálica, o que permite estabelecer um elo com a crescente influência das regiões provincianas na participação política no Império Romano. Em continuidade, este autor discorre sobre o alcance que as escolas de retórica, sobretudo as gaulesas, tiveram na questão da fundamentação de normas e hábitos escolares em relação às práticas de eloqüência e exercício da oratória por todo o império.

Neste sentido, tornou-se possível estabelecer semelhanças estilísticas entre os discursos panegirísticos selecionados, nos quais seus oradores desempenham com desenvoltura as regras da retórica empregadas neste gênero laudatório. Em todas estas obras o elogio ao imperador permanece como eixo indispensável e importante do discurso, pois será através da construção da sua imagem que os panegiristas irão estruturar as argumentações que fundamentavam ideologicamente o Dominato.

Acredita-se que estes discursos panegirísticos tenham sido elaborados com base em um mesmo arquétipo, e o fato de seus autores também serem provenientes de uma mesma região possibilita o desenvolvimento de uma questão centrada nas disputas que

${ }^{4}$ GALlETIER, E. Panégyriques Latins. Paris: Société d’edition "Les Belles Lettres”, 1952. Tomo I, p. VII-XVI. 
objetivavam uma maior influência e participação desta elite provinciana dentro da política imperial.

Neste sentido, além de terem como objetivo comum a legitimação de um governo monárquico, os oradores procuravam supervalorizar suas posições através da normatização de condutas por valores morais que conduziam as práticas aristocráticas nas províncias.

Dentre as obras que homenageiam Constantino, somente o "Panegirico de Constantino Augusto", pronunciado no ano de 321 d.C., chegou aos dias atuais com a autoria conhecida. Contudo, este elemento não nos possibilita extrair informações mais concretas e qualitativamente superiores do que os outros textos com autoria desconhecida, pois o que sabemos a mais é praticamente só o nome do autor: Nazário.

Apesar desta ausência nominal do autor do panegírico do ano de 310 d.C. "Panegírico de Constantino", não podemos considerar este fator como um entrave na análise, ou uma impossibilidade de se executar com eficiência a mesma. A partir das considerações realizadas sobre a eficácia e importância dos discursos como agentes de promoção ideológica, é possível identificar na própria definição do discurso panegíristico elementos que identifiquem a posição social do orador e sua colocação enquanto porta voz dos anseios de um grupo específico, principalmente ao considerarmos a questão da distinção social amparada pelo privilégio da educação.

$\mathrm{Na}$ estrutura dos discursos podem ser encontrados elementos utilizados pelo autor que o caracteriza enquanto participante de uma dada formação social, que no caso do nosso estudo, remete a fundamentação ideológica do Dominato, ou seja, a defesa da manutenção de um sistema imperial centralizado no monarca.

Como estes discursos foram pronunciados em sua maioria na presença dos imperadores homenageados, os oradores aproveitavamse deste tipo de situação para incorporar no corpo do discurso algumas aspirações particulares, o que nos auxilia em grande medida na identificação de elementos da vida deste autor. 
No caso do discurso do ano de 310 d.C. "Panegirico de Constantino", o orador permitirá o conhecimento, entre outros elementos, de sua cidade natal, a provável data de seu nascimento e de funções administrativas ocupadas por ele, seu filho e seus discípulos.

Desta forma, procuramos ao longo deste artigo discorrer que uma vez que produção panegirística não estava desvinculada das questões sociais e políticas no Império, ela tinha como principal objetivo, adequar a teoria do poder imperial à nova realidade que se formulava no século IV d.C.. Neste sentido, pôde-se compreender que a elaboração destes discursos ficava condicionada a uma função propagandística da política imperial, o que no século IV d.C. focavase na concentração de poder nas mãos de um único monarca, em busca de uma unidade política. Função esta que devido sua importância, não poderia ser atribuída aleatoriamente, desta forma, a autoria dos panegíricos ficava limitada a um pequeno grupo que participava, ou ao menos concordava, com a condução desta política imperial rumo ao Dominato.

\section{BIBLIOGRAFIA}

GALLETIER, E. Panégyriques Latins. Paris: Société d’edition “Les Belles Lettres”, 1952. Tomo I e II.

LLORENTE, Victor-Jose H. Biografos y Panegiristas Latinos. Madrid: Aguilar, 1969.

CARVAlHO, M. M. de. Paidéia e retórica no séc. IV d. C.: a construção da imagem do imperador Juliano segundo Gregório de Nazianzeno. 234 f. Tese (Doutorado em História Econômica) Faculdade de Filosofia Letras e Ciências Humanas, Universidade de São Paulo. São Paulo, 2002.

ESCRIBANO, M. V. Usurpación y religión en el s.IV D. de C.: paganismo, cristianismo y legitimactión política. In: BLANCO, A. G. Antigüedad y cristianismo: monografías históricas sobre la 
antigüedad tardía. Murcia: Universidade de Murcia, 1990. P. 247272.

FIORIN, J. Linguagem e ideologia. São Paulo: Editora Ática, 2003. FRIGHETTO, R. Cultura e poder na Antigüidade Tardia ocidental. Curitiba: Juruá, 2003.

. Imperium et orbis: conceitos e definições a partir das fontes tardo-antigas ocidentais (séculos IV/VII). Comunicação; Facetas do Império na História. Programa de Pós-Graduação em História Universidade Federal do Paraná: Curitiba, 2006.

GERVÁS, Manuel J. Rodrigues. Propaganda Politica y Opinión Pública en los panegiricos latinos del bajo império. Salamanca: Universidade de Salamanca,1991.

GONÇALVES, A. T. M. A legitimação do poder imperial e os problemas sucessórios nos breviários de História Romana produzidos no IV século d.C. In: História Revista - Revista do Departamento de História e do Programa de Pós-Graduação em História. Goiânia, v.11. n. 1, p. 01-15, jan./jun. 2006.

HIDALGO DE LA VEGA, M. J. El intelectual, la realeza y el poder político em el Império Romano. Salamanca: Universidad de Salamanca, 1995.

OLIVEIRA, M. A. M. O Império Romano e o Reino dos Céus: a construção da imagem sagrada do imperador em De Laudibus Constantini, de Eusébio de Cesaréia. 159 f. Dissertação (Mestrado em História) - Centro de Ciências Humanas e Naturais. Universidade Federal do Espírito Santo: Vitória, 2005.

SILVA, G. V. Reis, santos e feiticeiros: Constâncio II e os fundamentos místicos da basiléia 337-361. Vitória: Edufes, 2003.

. Motivações e procedimentos dos levantes populares urbanos no IV século. In: Phoînix / UFRJ, Rio de Janeiro, p. 157-168, 1997.

. A Domus Imperial e o fenômeno das usurpações no século IV. In: Phoînix / UFRJ, Rio de Janeiro, p. 73-84, 1995.

. Interesses subjacentes e interesses manifestos no contexto das usurpações romanas (284-395 d.C.). In: Phoînix / UFRJ, Rio de Janeiro, p. 91-100, 1996. 
SILVA, G. V. da; MENDES, N. M. Repensando o Império Romano: perspectivas socioeconômicas, política e cultural. Rio de Janeiro e Vitória: Maud Editora e EDUFES, 2006.

TAVEIRA, C. O modelo político da autocracia Bizantina: fundamentos ideológicos e significado histórico. 405 f. Tese (Doutorado em História) - Programa de Pós-Graduação em História. Universidade de São Paulo: São Paulo, 2002. 